\title{
Aortic root reoperations after pulmonary autograft implantation
}

\author{
J. A. Bekkers, MD, ${ }^{\mathrm{a}}$ L. M. A. Klieverik, MD, PhD, ${ }^{\mathrm{b}}$ G. Bol Raap, MD, PhD, ${ }^{\mathrm{a}}$ J. J. M. Takkenberg, MD, \\ $\mathrm{PhD},{ }^{\mathrm{a}}$ and A. J. J. C. Bogers, $\mathrm{MD}, \mathrm{PhD}^{\mathrm{a}}$
}

Objective: To report the results of aortic root reoperations after pulmonary autograft implantation.

\begin{abstract}
Methods: All consecutive patients in our prospective Ross research database were selected for analysis, and additional information for patients requiring reoperation was obtained from the hospital records.
\end{abstract}

\begin{abstract}
Results: From 1988 to 2009, 155 pulmonary autograft operations were performed. During this period, 41 patients required reoperation for aortic root dilatation and/or autograft valve insufficiency, in 8 patients combined with pulmonary allograft dysfunction. The freedom from autograft reoperation rate was $86 \%$ (standard error, $3.3 \%$ ) after 10 years and $52 \%$ (standard error, $6.6 \%$ ) after 15 years. The median interval to reoperation was 15.3 years. During reoperation, 39 patients underwent aortic root replacement (mechanical conduit, 31; stentless root, 2; allograft, 3; and valve sparing, 3), and 2 patients underwent valve replacement. In 8 patients this was combined with pulmonary allograft replacement. The technical difficulties encountered included bleeding at the sternal re-entry in 5 patients. No 30-day mortality occurred. The postoperative complications included reexploration for persistent blood loss in 3 patients and cerebrovascular accident in 3 patients. Two patients died during the follow-up period. The survival rate after reoperation was $94 \%$ (standard error, $4.1 \%$ ) at 5 years.

Conclusions: An increasing number of patients requires reoperation after pulmonary autograft implantation. These reoperations can be done with very low mortality and morbidity and excellent follow-up results. (J Thorac Cardiovasc Surg 2010;140:S58-63)
\end{abstract}

Pulmonary autograft implantation (the Ross operation) is an attractive option for aortic valve replacement, especially in children and young adults. ${ }^{1}$ The operative mortality and longer term results have been very satisfactory. A major drawback of this operation, however, is the progressive dilatation of the autograft root, often combined with autograft valve insufficiency, necessitating reoperation. Reoperations after previous aortic root surgery are complex and carry increased operative risks. ${ }^{2-5}$ In particular, reopening the chest, with the possible adherence of the dilated aorta to the sternum and the need for mobilization and reimplantation of the coronary arteries might contribute to the high-risk character of these reoperations and, therefore, the greater expected mortality risk in reoperative patients. In our center, a high volume of pulmonary autograft procedures was performed in the past 2 decades. ${ }^{6}$ Re-replacement of the aortic root will usually be performed using implantation of a valved conduit; however, recently, valve-sparing procedures after previous aortic root replacement have also been introduced. ${ }^{7}$

The purpose of the present study was to analyze the need for aortic root reoperations after pulmonary autograft

From the Department of Cardio-Thoracic Surgery ${ }^{a}$ and the Department of Cardiology, ${ }^{\mathrm{b}}$ Erasmus University Medical Center, Rotterdam, The Netherlands.

Disclosures: J. A. Bekkers, L. M. A. Klieverik, G. Bol Raap, J. J. M. Takkenberg, and

A. J. J. C. Bogers have nothing to disclose with regard to commercial support.

Received for publication April 27, 2010; revisions received July 23, 2010; accepted

for publication July 30, 2010.

Address for reprints: Jos A. Bekkers, MD, Department of Cardio-Thoracic Surgery,

Bd 571, Erasmus University Medical Center Rotterdam, P.O. Box 2040, 3000

CA Rotterdam, The Netherlands (E-mail: j.a.bekkers@erasmusmc.nl).

0022-5223/\$36.00

Copyright (C) 2010 by The American Association for Thoracic Surgery doi:10.1016/j.jtcvs.2010.07.065 implantation and to report our experience with these reoperations.

\section{MATERIALS AND METHODS Patients}

From 1988 to 2009, 155 consecutive patients underwent the Ross operation at our institution. In 149 patients, we performed a full root implantation; in 6 patients, an inclusion cylinder was implanted. The preoperative patient characteristics are listed in Table 1. Twelve patients underwent previous aortic valve replacement: 6 subcoronary homografts, 3 biologic prostheses, and 3 mechanical prostheses were used. The institutional review board approved the present prospective follow-up study and waived the need for informed consent.

\section{Primary Operation}

The perioperative data are listed in Table 2. All surgical procedures were performed with cardiopulmonary bypass with moderate hypothermia. In 3 patients, additional deep hypothermia with total circulatory arrest was needed for surgery on the aortic arch. Crystalloid cardioplegia and topical cooling were used for myocardial protection.

In most patients, the root replacement technique was used, and the pulmonary autograft was inserted at the level of the annulus, with care taken to reduce the subannular muscular rim of the autograft to 3 to $4 \mathrm{~mm}$. The proximal suture line of the autograft was constructed, with interrupted sutures in $21 \%(\mathrm{n}=30)$ of the procedures and running sutures in the remainder. In 2 patients, an autologous pericardial strip supported the proximal suture line.

In all patients, the right ventricular outflow tract was reconstructed using an allograft. In $98 \%$, a pulmonary allograft was used, and $99 \%$ of the allografts used were cryopreserved. Three patients required concomitant coronary artery bypass grafting because of a procedural complication. The details of these patients have been previously reported. ${ }^{6}$

\section{Reoperations}

All reoperations were performed through a median sternotomy, with cardiopulmonary bypass and moderate hypothermia. We mostly used 


\section{Abbreviations and Acronyms \\ $\mathrm{HR}=$ hazard ratio \\ $\mathrm{CI}=$ confidence interval}

central cannulation in the ascending aorta and right atrium or caval veins. To anticipate possible perforation of the heart or aorta when reopening the chest, we instituted cardiopulmonary bypass with canulation of the femoral vessels and deep cooling in 4 patients before performing the sternotomy. Crystalloid cardioplegia and topical cooling were used for myocardial protection. Total circulatory arrest with deep hypothermia was needed in 11 patients, with ascending aorta or arch reconstruction, necessary to correct ascending aortic or arch dilatation.

In patients without aortic root dilatation, the valve leaflets were excised, followed by mechanical valve implantation. The neo-aortic root was in most cases dilated without any signs of root or valve calcification. After opening the autograft root, the autograft valve leaflets were inspected, and most of them were excised and the coronary buttons mobilized. Excess autograft wall tissue was removed, leaving parts of the autograft at the annular level in situ. Standard valved conduit implantation was performed. When appropriate, the valve leaflets were spared, using the aortic valve reimplantation technique. ${ }^{8}$

\section{Follow-up}

All patients were followed up prospectively and annually contacted and interviewed by telephone. Patients older than 16 years underwent standardized echocardiography biannually. ${ }^{9}$ In the case of suspected complications, the attending physician was contacted for verification. Valve-related events were defined according the 2008 guidelines for reporting morbidity and mortality after cardiac valvular operations. ${ }^{10}$ Failure of the autograft or pulmonary allograft was determined at reoperation or death. The recording of patient survival was started at the Ross operation and ended at death or the last follow-up visit. Survival of the autograft or pulmonary allograft was started at surgery and ended when reoperation or reintervention was necessary, the patient died, or the last follow-up visit. Two patients moved abroad and were lost to follow-up.

The database was frozen on December 1, 2009. The total follow-up was 1694 patient-years and was $97 \%$ complete. The mean follow-up duration was 11.0 years (range, $0-20.4$ years).

\section{Statistical Analysis}

Descriptive statistical analysis of the perioperative data was done. Continuous data are displayed as mean \pm 1 standard deviation. Discrete data are presented as proportions. Cumulative survival and freedom from reoperation or reintervention were analyzed using the Kaplan-Meier method. Survival is displayed as the proportion \pm standard error. The log-rank test was used to compare the Kaplan-Meier curves.

The Cox proportional hazards regression analysis was used to evaluate the following variables as predictors for autograft reoperation over time: previous aortic valve replacement, patient age, bicuspid valve disease, surgical technique used (root replacement versus inclusion cylinder technique), and hemodynamic diagnosis (regurgitation versus stenosis versus combined regurgitation and stenosis). First, all variables were entered into a univariate analysis. Next, all variables that were significant on univariate analysis or showed a tendency toward significance $(P \leq .20)$ were forced into the multivariate Cox regression analysis (enter method). The proportional hazards assumption was assessed for each variable through graphic inspection of the log minus log survival and the linearity assumption for continuous variables though the partial residuals. No indication was seen of a violation of the assumptions. All testing was performed 2-sided. For all data analysis, the Statistical Package for Social Sciences, version 15.0.0, for Windows (SPSS, Chicago, Ill) was used.
TABLE 1. Preoperative patient characteristics $(n=155)$

\begin{tabular}{|c|c|}
\hline Characteristic & Value \\
\hline \multicolumn{2}{|l|}{ Age (y) } \\
\hline Mean $\pm \mathrm{SD}$ & $21.4 \pm 13.7$ \\
\hline Range & $0.05-52$ \\
\hline \multicolumn{2}{|l|}{ Age group (\%) } \\
\hline $0-16$ & $39(\mathrm{n}=61)$ \\
\hline$>16$ & $61(\mathrm{n}=102)$ \\
\hline Male gender & $66(n=96)$ \\
\hline Previous cardiac surgery* & $33(\mathrm{n}=51)$ \\
\hline Previous aortic valve replacement & $8(\mathrm{n}=12)$ \\
\hline Previous valvulotomy & $18(\mathrm{n}=28)$ \\
\hline Previous balloon dilatation & $22(\mathrm{n}=33)$ \\
\hline \multicolumn{2}{|l|}{ Etiology } \\
\hline Endocarditis & $5(\mathrm{n}=8)$ \\
\hline Congenital (including bicuspid) & $75(\mathrm{n}=117)$ \\
\hline Other (mainly prosthetic valve) & $12(\mathrm{n}=18)$ \\
\hline Degenerative/rheumatic & $7(\mathrm{n}=11)$ \\
\hline Aneurysm/dissection & $1 \%(\mathrm{n}=1)$ \\
\hline \multicolumn{2}{|l|}{ Diagnosis } \\
\hline Aortic valve regurgitation & $29(\mathrm{n}=45)$ \\
\hline Aortic valve stenosis & $32(\mathrm{n}=50)$ \\
\hline $\begin{array}{l}\text { Aortic valve regurgitation plus } \\
\text { aortic valve stenosis }\end{array}$ & $39(\mathrm{n}=60)$ \\
\hline \multicolumn{2}{|l|}{ Systolic LVF $\dagger(n=148)$} \\
\hline Good & $83(n=124)$ \\
\hline Impaired & $12(\mathrm{n}=16)$ \\
\hline Moderate/poor & $5(\mathrm{n}=8)$ \\
\hline Sinus rhythm & 100 \\
\hline \multicolumn{2}{|l|}{ Creatinine $(\mu \mathrm{mol} / \mathrm{L})(\mathrm{n}=145)$} \\
\hline Mean \pm SD & $62 \pm 24$ \\
\hline Range & $12-157$ \\
\hline \multicolumn{2}{|l|}{ NYHA class $(\mathrm{n}=148)$} \\
\hline I & $42(n=62)$ \\
\hline II & $36(\mathrm{n}=54)$ \\
\hline III & $16(\mathrm{n}=24)$ \\
\hline IV-V & $5(\mathrm{n}=8)$ \\
\hline Ventilation support & $3(n=4)$ \\
\hline \multicolumn{2}{|l|}{ Operation type } \\
\hline Emergency $(<24$ h) & $1(\mathrm{n}=2)$ \\
\hline Urgent & $16(n=25)$ \\
\hline Elective & $83(\mathrm{n}=128)$ \\
\hline
\end{tabular}

$L V F$, Left ventricular function; $N Y H A$, New York Heart Association. *Some patients had other previous cardiac surgery (ie, ventricular septal defect closure, subvalvular membrane resection. $†$ Systolic left ventricular function based on qualitative echocardiographic estimations.

\section{RESULTS}

\section{Early Mortality After Primary Operation}

The early mortality rate at 30 days was $2.6 \%$ (4 patients). Two patients, both female, died during surgery. Of these 2 patients, 1, a 40-year-old patient, died of low output failure and the other patient (4 months old) died of heart failure and severe arrhythmias. A third patient, a 26-year-old man, died of massive pulmonary emboli shortly after surgery. Finally, a 24-year-old female patient with Turner syndrome and extreme left ventricular hypertrophy died of mediastinitis and sepsis 13 days after surgery. 
TABLE 2. Perioperative details $(\mathbf{n}=\mathbf{1 5 5})$

\begin{tabular}{lc}
\hline \multicolumn{1}{c}{ Variable } & Patients $(\%)$ \\
\hline Aortic valve & \\
$\quad$ Bicuspid & $60(\mathrm{n}=93)$ \\
Tricuspid & $32(\mathrm{n}=49)$ \\
$\quad$ Prosthesis & $8(\mathrm{n}=12)$ \\
Surgical technique & \\
$\quad$ Autograft root replacement & $96(\mathrm{n}=149)$ \\
Inlay autograft & $4(\mathrm{n}=6)$ \\
Concomitant procedures & \\
CABG & $2(\mathrm{n}=3)$ \\
LVOT enlargement & $12(\mathrm{n}=19)$ \\
$\quad$ Mitral valve surgery & $1(\mathrm{n}=2)$ \\
Other* & $12(\mathrm{n}=18)$ \\
CPB time (min) & $201(114-685)$ \\
Crossclamp time (min) & $141(90-240)$ \\
Circulatory arrest (min; $\mathrm{n}=3)$ & $30(11-64)$ \\
Complications & \\
Bleeding/tamponade & $13 \%(\mathrm{n}=20)$ \\
Pacemaker & $1 \%(\mathrm{n}=1)$ \\
Perioperative MI & $1 \%(\mathrm{n}=1)$ \\
Early mortality & $2.6 \%(\mathrm{n}=4)$ \\
\hline CABG, Coronary bypass operation; $L V O T$, left ventricular outflow tract; $C P B$, cardio- \\
pulmonary bypass; $M I$, myocardial infarction. Included patients requiring tailoring \\
of ascending aorta or subvalvular membrane resection.
\end{tabular}

\section{Late Survival After Primary Operation}

During follow-up, 7 more patients died. Of the 7 deaths, 3 were valve-related and 4 were nonvalve-related deaths. One valve-related death was a 12-year-old girl with severe juvenile rheumatic disease and severe aortic valve regurgitation and mitral valve incompetence, resulting in progressive heart failure. She died 6 months after surgery of recurrent rheumatic disease. ${ }^{11}$ The other 2 valve-related deaths were both sudden, unexpected, and unexplained deaths. One adult patient died 13.8 years after autograft implantation, and one died 10.8 years after autograft implantation and 1 year after autograft replacement for progressive neo-aortic dilatation and regurgitation.

The causes of the nonvalve-related deaths included septic shock (Candida albicans) in 1 infant 51 days after autograft implantation, heart failure resulting in cardiogenic shock in another infant 1.7 years after autograft implantation, acute myocardial infarction in 1 adult patient 4.7 years after autograft implantation and 2 months after autograft replacement for progressive neo-aortic dilatation and regurgitation, and heart failure with normal functioning autograft in 1 adult patient 16.2 years after autograft implantation.

The overall 15 -year survival rate was $92 \% \pm 1.8 \%$ (Figure 1).

\section{Reoperation}

A total of 41 patients underwent reoperation on the autograft, of which 3 were in other institutions. All patients who required reoperation of the autograft had originally

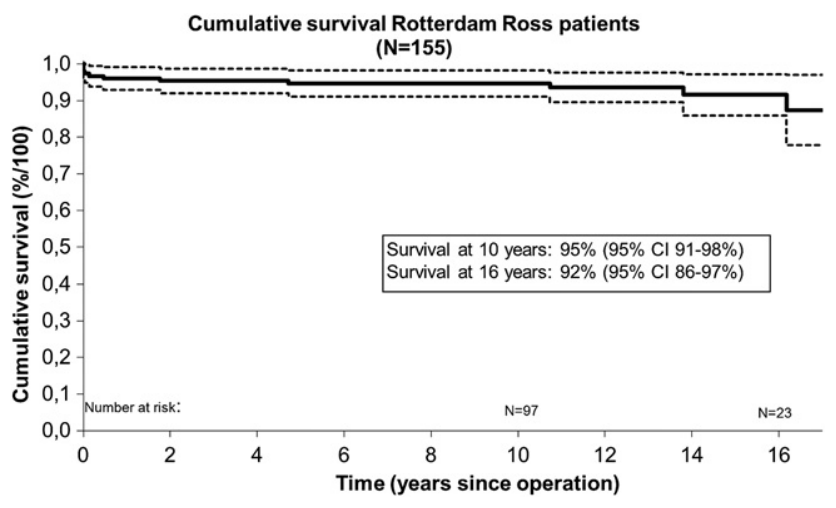

FIGURE 1. Observed cumulative survival after the Ross operation.

undergone full root implantation. The mean age was 36 years (range 16-64 years) at reoperation. Of these 41 patients, 33 required isolated pulmonary autograft reoperation, 8 required simultaneous replacement of both the pulmonary autograft and the allograft.

Progressive dilatation of the neo-aortic root combined with aortic regurgitation was the main cause for autograft reoperation. The causes for allograft replacement were mainly structural failure, calcification, or senile degeneration of the valve. The details of the reoperative procedures are listed in Table 3. In 1 patient, an aortic valve replacement was performed 8 years after the primary Ross operation for neo-aortic regurgitation with a moderately dilated neo-aorta, followed by mechanical conduit implantation 4 years later for progressive ascending aortic dilatation. The technical difficulties encountered at these reoperations were accidental injury of the aorta or pulmonary artery at reopening the chest in 5 patients, in 3 patients requiring emergency institution of cardiopulmonary bypass using the femoral vessels. No reoperative mortality occurred.

TABLE 3. Reoperation characteristics

\section{Characteristic}

Patients (n)

Indication for reoperation

Aortic root dilatation with aortic regurgitation 34

Isolated aortic root dilatation

Isolated aortic regurgitation

Aortic root procedure

Aortic root replacement

Allograft

Valved conduit

Stentless root

Valve sparing

Aortic valve implantation

Additional procedures

Pulmonary allograft replacement $\quad 8$

Allograft

Valved conduit

Mitral valve repair/replacement 


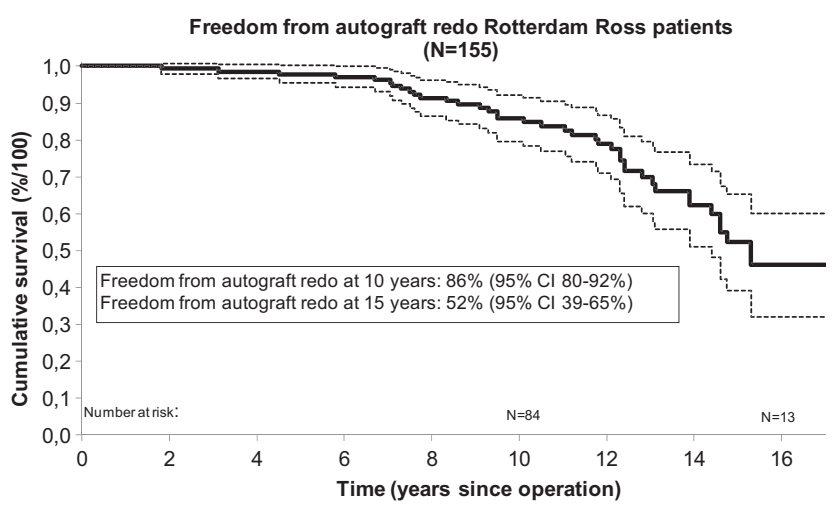

FIGURE 2. Overall freedom from autograft reoperation.

Postoperative morbidity included rethoracotomy for persistent blood loss in 3 patients $(7.3 \%)$ and stroke in 3 patients $(7.3 \%)$. In 1 patient, the stroke was related to accidental injury of the pulmonary allograft and hypovolemic shock at reopening of the chest.

Two patients died after these reoperations. One patient died 3 months postoperatively of a myocardial infarction. The second patient died 17 months postoperatively; the death was sudden and unexplained. The freedom from reoperation for autograft failure rate at 10 years was $86 \% \pm$ $3.3 \%$ and was $52 \% \pm 6.6 \%$ at 15 years (Figure 2). The rate of freedom from autograft reoperation was comparable between patients younger than 16 years and those aged 16 years or older at surgery (log-rank test, chi-square 2.288; $P=.13)$.

The only univariate predictor of autograft reoperation was preoperative pure aortic regurgitation (hazard ratio [HR], 1.86; 95\% confidence interval [CI], 0.99-3.49; $P=$ $.05)$. Adult patient age showed a tendency toward greater autograft reoperation rates (HR, 1.73; 95\% CI, 0.84-3.56; $P=.14$ ). After multivariate analysis, the adult patient age was no longer significant (HR, 1.53; 95\% CI, 0.72-3.21; $P=.26$ ), and pure aortic regurgitation showed a trend toward greater autograft reoperation rates (HR, 1.70; 95\% CI, 0.89-3.24; $P=.11$ ).

\section{Other Valve-Related Events}

During follow-up, 2 patients developed endocarditis (0.11\%/patient-year), complicated by a stroke in 1 patient. In 1 patient, allograft endocarditis occurred and was treated with antibiotics $(0.06 \%$ /patient-year). One patient developed pulmonary emboli $(0.06 \%$ /patient-year). Bleeding events, valve thrombosis, or nonstructural failure was not observed.

\section{Functional Status at Follow-up}

At the last follow-up visit, $95 \%$ of the patients were in New York Heart Association class I or II, and 5\% of patients $(n=6)$ were in New York Heart Association class
III-IV owing to aortic regurgitation or heart failure. Finally, $5 \%$ of the patients had moderate to severe aortic regurgitation, $1 \%$ had moderate to severe pulmonary regurgitation, and $7 \%$ of the patients had moderate to severe pulmonary stenosis.

\section{DISCUSSION}

Although the Ross operation has provided very satisfactory results in the first postoperative decade, over time an increasing number of patients will require reintervention. Of our series of 155 primary Ross operations, 41 patients underwent reintervention on the aortic root with a median interval to reintervention of 15.3 years (range, 1.8-18.7 years). Since the completion of the present study, 4 additional patients were scheduled for reoperation. The freedom from reoperation rate at 10 years was $86 \%$. These results are comparable to those of other series. ${ }^{12,13}$ Most of our reoperations occurred in the second decade after the Ross operation. In a meta-analysis of 17 consecutive series of both children and adults, the yearly rate of structural valve deterioration or nonstructural valve deterioration for the autograft valve was estimated to be $1.15 \%$ (95\% CI, 1.06 $2.06 \%) .{ }^{1}$ In our series, with a longer follow-up than other series in the meta-analysis, we found a yearly rate of structural valve deterioration or nonstructural valve deterioration of $1.81 \%$, well within the $95 \%$ CI of the pooled series. ${ }^{6}$

Given that in our institution, none of the autograft roots were implanted in an intra-annular method and no proximal support was used, technical adaptations of the pulmonary root implantation might be helpful in preventing, or at least delaying, these reoperations. Charitos and colleagues ${ }^{14}$ reported on the results of the German-Dutch Ross Registry. They found that reinforcement of the proximal suture line in a full root Ross operation leads to a reduction of the reoperation rate at 10 years of follow-up. ${ }^{14}$ In their series, the mean follow-up duration of only 8 years in the patients with a reinforced proximal suture line was shorter than in patients without reinforcement. Conceptually, it is hard to understand by which mechanism, that the reinforcement of the proximal suture line only will prevent the sinuses of Valsalva and distal parts of the pulmonary autograft root from dilation. Others have advocated reinforcement of the entire pulmonary root with a prosthetic graft. ${ }^{15,16}$ These advanced techniques for the Ross operation might be attractive additions to the operation in an adult patient population. In growing children, however, some degree of dilatation or growth of the autograft will be advantageous to the patient. It is hard to foresee what technical modifications of the operation would allow for some degree of diameter augmentation of the implanted root but would prevent aneurysmal dilatation and subsequent valve dysfunction.

In the present series, we had no mortality in 41 reoperations. The operative mortality rate after previous ascending 
aortic or aortic valve surgery is reported to be $5.4 \%$ to $17.9 \% .^{2-5}$ Most of these series are combined series of patients with different types of previous aortic root procedures. The risk factors for mortality are mostly advanced age and the need for coronary revascularization, either planned or unforeseen. ${ }^{3-5}$ In our series of exclusively reoperations after pulmonary autograft implantation, the patients were relatively young, and no coronary revascularization was necessary. In these reoperations, the coronary buttons are usually relatively easy to prepare, because, in contrast to reoperations after previous allograft implantation, aortic wall calcification is absent.

Our experience has shown that the reoperations can be performed safely with little morbidity and no reoperative mortality, but with a few surgically challenging technical difficulties, the consequences of which can be avoided by paying particular attention to the reopening of the chest. Because in most patients, the aortic root and ascending aorta are dilated, these structures can become adherent or very close to the posterior aspect of the sternum. Preoperative computed tomography scanning might help identify patients at risk of aortic injury at reopening the chest. In these patient, elective femoral vessel canulation will allow safe entry into the chest. Nevertheless, we encountered accidental aortic or pulmonary artery injury in 5 patients, requiring emergency installation of cardiopulmonary bypass with femoral vessel canulation. From this experience, we routinely performed computed tomography of the chest in the preoperative workup of these patients.

Because the most prominent indication for reoperation is aortic root dilatation, aortic root replacement is required. Only 2 patients in our series had structural valve dysfunction without severe aortic dilatation. In these patients, insertion of an aortic valve prosthesis in the pulmonary autograft root was possible. In 1 of these patients, a moderately dilated ascending aorta was untouched at reoperation, but progressive ascending aortic dilatation necessitated ascending aortic replacement 4 years later. In patients with aortic root dilatation without structural aortic valve dysfunction, a valve-sparing root replacement might be possible. Our systematic biannual echocardiographic follow-up protocol helps in identifying asymptomatic patients with significant aortic root dilatation. These patient can undergo elective reoperation before the onset of potentially lethal aortic complications, such as aortic dissection. Performing reoperation before severe aortic insufficiency has developed could enhance the possibilities for valve-sparing procedures and prevent irreversible myocardial damage.

The indication for a Ross operation has been a matter of debate, and recent reports have shown an increasing incidence of reoperations after pulmonary autograft implantation. ${ }^{1,6,17}$ Our results have shown a substantial proportion of patients requiring reoperation after a Ross operation. The present report provides information about the risks of these reoperations and might therefore be useful in determining the preferred choice for a valve substitute in patients with aortic valve disease. In adults patients, our initial enthusiasm for the Ross operation has tempered. We have not performed a Ross operation in an adult patient in the past 7 years. In children and young adults, however, the pulmonary autograft might still be the preferred valve substitute, given the excellent short- and long-term results and the lack of a reasonable alternative. The decision for a valve substitute should take into account, weighing the risks and benefits of the available treatment strategies, combined with careful elicitation of patient preferences to ascertain patient-tailored optimal treatment selection.

\section{CONCLUSIONS}

In our prospective cohort, reoperation of the autograft root was observed increasingly in the second decade after the Ross operation. Careful monitoring of patients over time and adequate timing of the reoperation and a surgical strategy tailored to the mode of autograft failure are the basic requirements for a safe and successful reoperation.

\section{References}

1. Takkenberg JJM, Klieverik LMA, Schoof PH, van Suylen RJ, van Herwerden LA, Zondervan PE, et al. The Ross procedure: A systematic review and meta-analysis. Circulation. 2009;119:222-8.

2. Szeto WY, Bavaria JE, Bowen FW, Geirsson A, Cornelius K, Hargrove WC, et al. Reoperative aortic root replacement in patients with previous aortic surgery. Ann Thorac Surg. 2007;84:1592-9.

3. Kirsch EW, Radu NC, Mekontso-Dessap A, Hillion ML, Loisance D. Aortic root replacement after previous surgical intervention on the aortic valve, aortic root, or ascending aorta. J Thorac Cardiovasc Surg. 2006;131:601-8.

4. Girardi LN, Krieger KH, Mack CA, Lee LY, Tortolani AJ, Isom OW. Reoperations on the ascending aorta and aortic root in patients with previous cardiac surgery. Ann Thorac Surg. 2006;82:1407-12.

5. Malvindi PG, van Putte BP, Heijmen RH, Schepens MAAM, Morshuis WJ. Reoperations on the aortic root: Experience in 46 patients. Ann Thorac Surg. 2010; 89:81-6.

6. Klieverik LMA, Takkenberg JJM, Bekkers JA, Roos-Hesselink JW, Witsenburg M, Bogers AJJC. The Ross operation: A Trojan horse? Eur Heart J. 2007;16:1993-2000.

7. Luciani BL, Viscardi F, Pilati M, Prioli AM, Faggian G, Mazzucco A. The RossYacoub procedure for aneurysmal autograft roots: A strategy to preserve autologous pulmonary valves. J Thorac Cardiovasc Surg. 2010;139:536-42.

8. David TE, Feindel M. An aortic valve sparing operation for patients with aortic incompetence and aneurysm of the ascending aorta. J Thorac Cardiovasc Surg. 1992;103:617-22.

9. Willems TP, Takkenberg JJM, Steyerberg EW, Kleyburg-Linkers VE, Roelandt JR, Bos E, et al. Human tissue valves in aortic position: Determinants of reoperation and valve regurgitation. Circulation. 2001;103:1515-21.

10. Akins CA, Miller DC, Turina MI, Kouchoukos NT, Blackstone EH, Grunkemeier GL, et al. Guidelines for reporting mortality and morbidity after cardiac valve interventions. J Thorac Cardiovasc Surg. 2008;135:732-8.

11. van Suylen RJ, Schoof PH, Bos E, Frohn-Mulder OME, den Hollander JC, Hertzberger-ten Cate R, et al. Pulmonary autograft failure after aortic root replacement in a patient with juvenile rheumatoid arthritis. Eur J Cardiothorac Surg. 1992;6: 571-2.

12. De Kerchove L, Rubay J, Pasquet A, Poncelet A, Ovaert C, Pirotte M, et al. Ross operation in the adult: Long-term outcomes after root replacement and inclusion techniques. Ann Thorac Surg. 2009;87:95-102.

13. Frigiola A, Ranucci M, Carlucci C, Giamberti A, Abella R, Di Donato M. The Ross procedure in adults: Long-term follow-up and echocardiographic changes leading to pulmonary autograft reoperation. Ann Thorac Surg. 2008;86:482-90. 
14. Charitos EI, Hanke T, Stierle U, Robinson DR, Bogers AJJC, Hemmer W, et al. Autograft reinforcement to preserve autograft function after the Ross procedure. Circulation. 2009;120(Suppl. 1):S146-54.

15. Carrel T, Schwerzmann M, Eckstein F, Aymard T, Kadner A. Preliminary results following reinforcement of the pulmonary autograft to prevent dilatation after the Ross procedure. J Thorac Cardiovasc Surg. 2008;136:472-5.
16. Juthier F, Banfi C, Vincentelli A, Ennezat P, Le Tourneau T, Pinçon C, et al. Modified Ross operation with reinforcement of the pulmonary autograft: Six-year results. J Thorac Cardiovasc Surg. 2010;139:1420-3.

17. David TE, Woo A, Armstrong S, Maganti M. When is the Ross operation a good option to treat aortic valve disease? J Thorac Cardiovasc Surg. 2010; 139:68-75. 